\title{
An Inexpensive Frame Grabber for the Microscopist
}

Richard S. Brown, MVA, Inc.

Having shopped for an inexpensive but powerful digital imaging system for the last four years, I have finally found a device that will satisfy even the most frugal budget. The Snappy Video Snapshot by Play, Incl, is a 24-bit true color frame grabber that plugs into your $\mathrm{PC}$ printer port. After plugging the Snappy device into your printer port (Figure 1) and spending approximately six minutes loading the Snappy software provided, you can connect a color or black and white camera, VCR, or television set and capture your first digital image. Because the device plugs into a printer port, it is completely portable. A switch box is needed if you will be changing between digital image acquisition and printing tasks frequently.

If all this sounds easy ... it is. If all this sounds expensive, it's not. The Snappy video frame grabber supports resolutions up to $1500 \times 1125$, has a preview mode $(160 \times 120)$ that allows you to focus your image prior to capturing it, and comes with additional software for special effects all for $\$ 189.00$ ! At this price anyone with a camera, $P C$ and a microscope can be collecting and archiving full color photomicrographs in a matter of minutes.

The easy to use setup screens (see Figures 2-4) allow the photomicrographer to preview an image prior to capture, adjust contrast and brightness, and even change and invert colors. Input sources are either NTSC or PAL (other options may be available). Resolutions of $1500 \mathrm{x}$ 1125 and $640 \times 480$ are available for still photomicrography. PC requirements include Windows 3.1, four megabytes of RAM, four megabytes of hard disk space, and a 486 processor or greater. Images can be stored as Windows Bitmap (*.bmp), JPEG (*.JPG), Zsoft PCX (*.pcx), TrueVision Targa (*.tga) and Aldus TIFF (*.tif). The manual is well written and loaded with information for the apprentice videographer and for the experienced user.

Unfortunately for instant film manufactures this device brings the cost of digital image acquisition to the bench level and beyond. Digital images will probably never replace film, they are not superior to film in resolution or in image rendering, but there is a place in the microscopist's lab for an inexpensive and fun frame grabber that can produce full color digital images in under a minute (highest resolution mode, eight frames sampled), that can be copied unlimited times and can be distributed for pennies. If I'm too late with this article and you have already purchased a video board for your $\mathrm{PC}$, I apologize. If you haven't opened the box yet, send it back and buy a Snappy. You can spend the $\$ 2,000-\$ 3,000$ youlll save on a better color camera for the lab. The Snappy Video Snapshot is an affordable and long awaited interface between the computer and the microscope. For further information, the manufacturer can be reached at:

\section{NORAM/Tracor Morthern EDS Repair}

Factory and field trained personnel with over 35 years total experience, located in the the Midwest, Southeast and on the West Coast, specializing in TN2000 and TN5500 repair, detector upgrades, data storage, imaging hardware and peripheral output devices - and used equipment resale.

Choose from a full maintenance or parts only contract, or on-demand service - at rates normally a fraction of others.

For further information, contact Doug Connors at:

\section{T Analyzer Service}

7897 Highway 19

Dane, W| 53529
Tel:: $(608) 798-2005$

Fax: (608)798-1675
Play, Incorporated

2890 Kilgore Road

Rancho Cordova, CA 95670-6133

(800)306-PLAY

At $\$ 189.00$ for the Snappy Video Snapshot and $\$ 14.95$ for 2 nd day Federa Express, I bought mine from:

LIBI Industries, LTD

63-53 252nd Street

Little Neck, NY 11362-2305

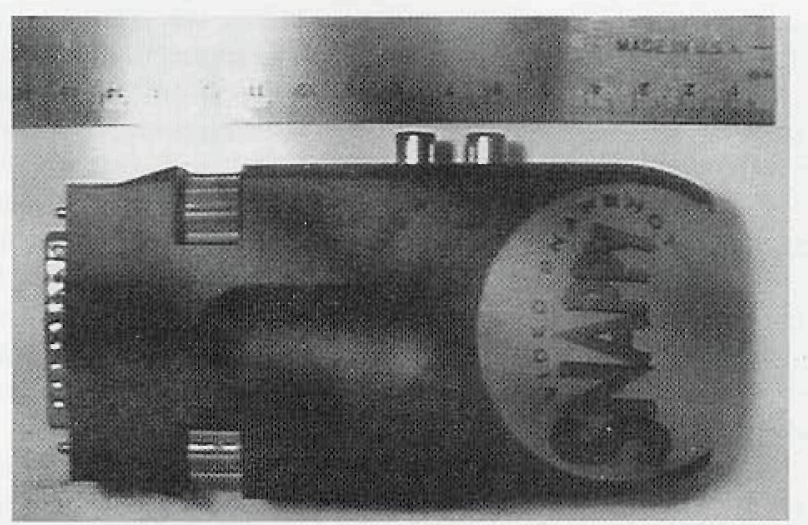

Figure 1. Snappy Video Snapshop hardware module. Module plugs into PC printer port. Nine volt battery is included. RCA jacks are for video source and video pass through to a TV monitor.

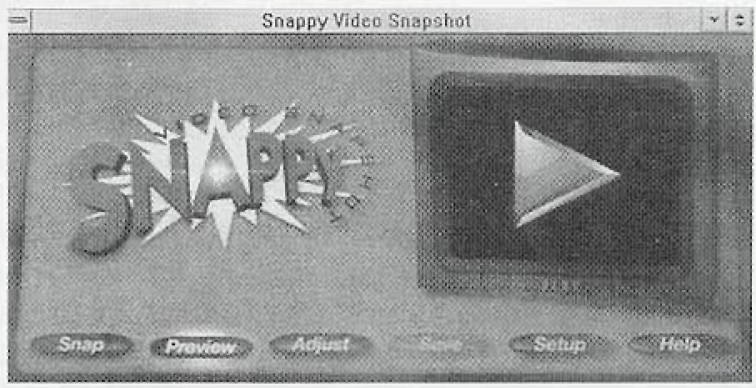

Figure 2. Snappy window in "preview" mode. Image will refresh on "TV" screen at about one frame per second for "live" focusing or other adjustments

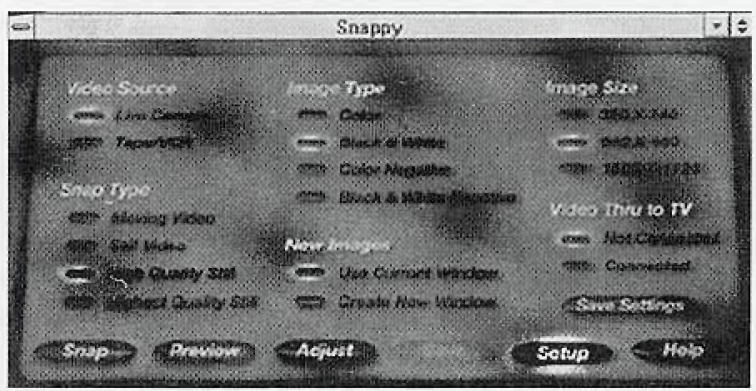

Figure 3. "SETUP" window allows selection of video source and image quality of image captured

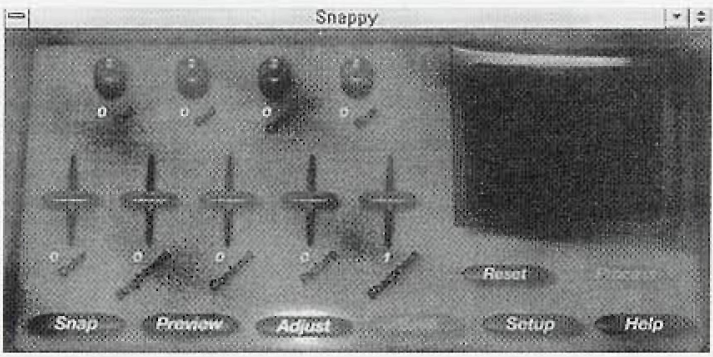

Figure 4. "ADJUST" window allows for software correction of captured image. No adjustments were necessary when I installed Snappy

Reprinted from the MICROSCOPE Vol. 44:1 (1996) 


\section{The original, uncompromising, nondestructive analytical tool from ElectroScan...}

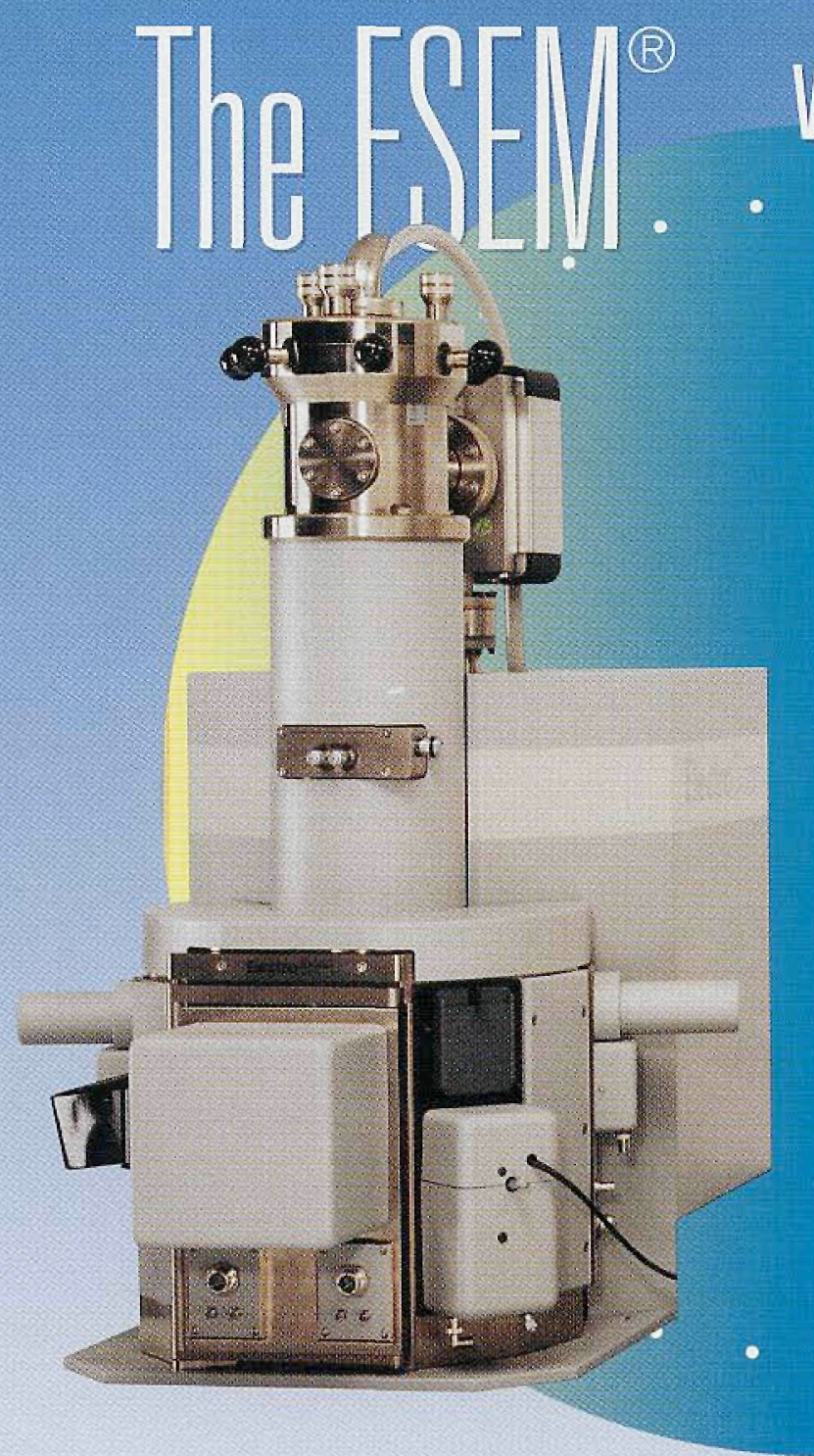

What do authors of over $98 \%$ of the scientific papers published on "environmental scanning electron microscopy" use to generate their data? You guessed it! The ESEM from ElectroScan.

That comes as no surprise to those who know about ElectroScan. Did you know ElectroScan was the first company to commercially introduce an Environmental Scanning Electron Microscope (ESEM) and the first to coin the now well-known acronym, ESEM? Did you know that ElectroScan is the only company that offers secondary imaging in a gas? Why? Because of our eight proprietary patents.

The next time you're in the market for a wet SEM, natural SEM, eco SEM, Iv SEM, or vp SEM, make sure you check out the difference the ElectroScan ESEM can make in your analysis:

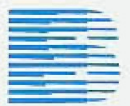

\section{ElectroScan ${ }^{\oplus}$ Corporation}

66 Concord Street, Wilmington, MA 01887 Tel (508)988-0055 Fax (508) 988-0062

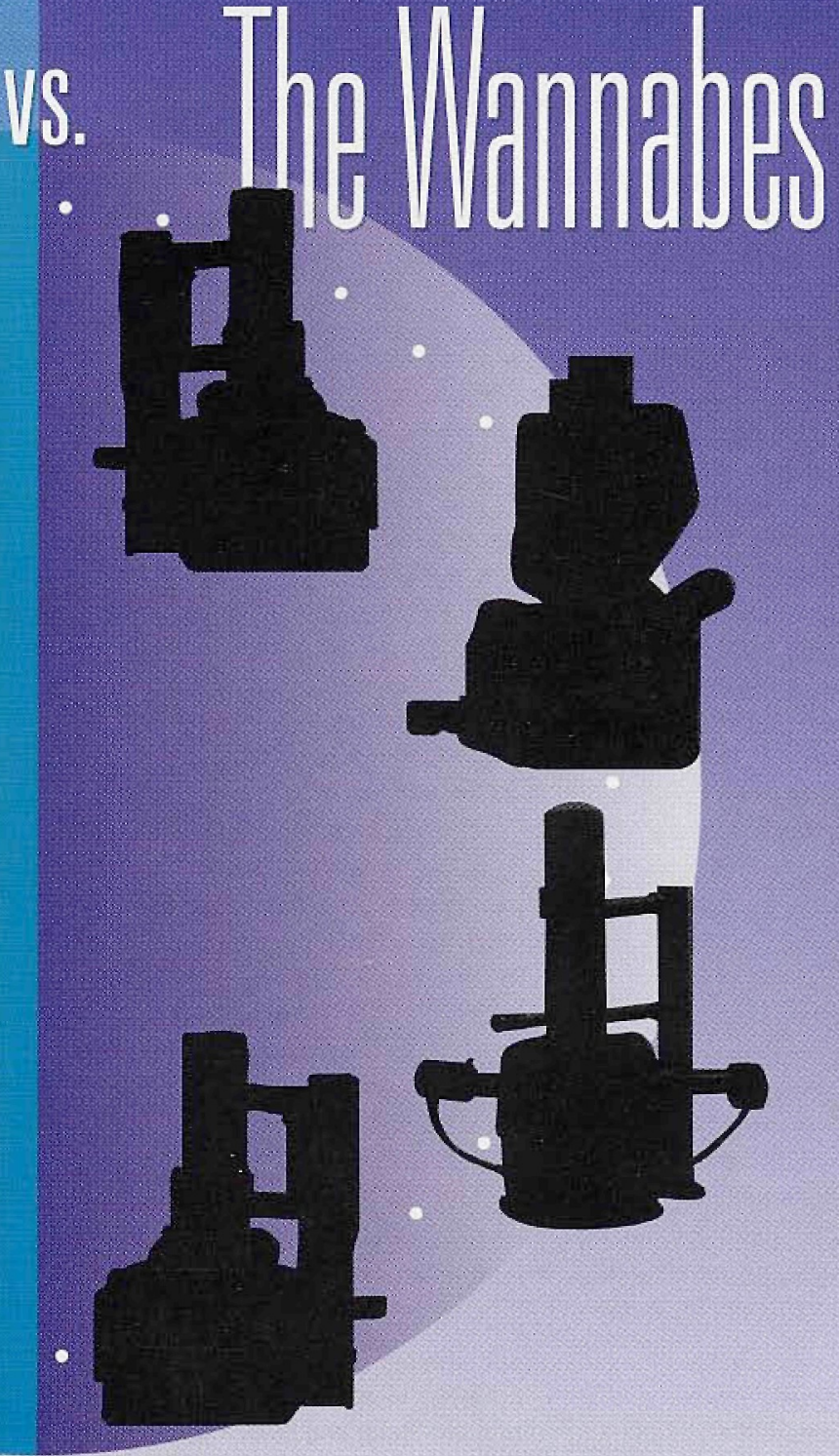

Feature

ElectroScan's ESEM The Wannabes

Secondary Imaging at High Pressure

\begin{tabular}{|c|c|c|}
\hline at High Pressurc & Yes & No \\
\hline $\begin{array}{l}\text { Variable Gis Pressure } \\
\text { up to } 50 \text { Torr }\end{array}$ & Yes & No \\
\hline $\begin{array}{l}\text { Controlled Real Time Hydration/ } \\
\text { Delrydration Experiments }\end{array}$ & Yes & $\mathrm{No}$ \\
\hline Best EDS Results in Gas Mode & Yes & $\mathrm{No}$ \\
\hline Backscattered Detection Only & No & Yes \\
\hline $\begin{array}{l}\text { Maximum Gas Pressure } \\
\text { of } 4 \text { Tori }\end{array}$ & No & Yes \\
\hline $\begin{array}{l}\text { Wet Samples Dry Out } \\
\text { in Seconds }\end{array}$ & $\mathrm{No}$ & Yes \\
\hline
\end{tabular}

The more you know about the original, uncompromising, nondestructive ElectroScan's ESEM ${ }^{\circ}$, the easier it will be to make this most important technical decision.

Seeing Things You've Never Seen Before ${ }^{8}$

Visit us on the World Wide Web-http://wwwelectroscancom 